\section{Brand positioning in higher education: the perception of Brazilian generational cohorts}

\author{
Cristina M. Ostermann" \\ Carlos Mello Moyano' \\ Jaime Laufer ${ }^{1}$
}

${ }^{1}$ UNISC, Department of Management, Santa Cruz do Sul, Brazil

\begin{abstract}
Purpose - The study aimed to evaluate how different Brazilian generational cohorts that have a direct relationship with the State University of Rio Grande do Sul (Universidade Estadual do Rio Grande do Sul - UERGS) perceive the brand positioning of the university.

Design/methodology/approach - A multi-method study with a qualitative and quantitative approach was performed using a sample of 273 individuals formed of students and staff of UERGS (professors, administrative staff and technicians, and managers).

Findings - The results of the research suggest that there is a difference in the perception of the brand positioning of UERGS between individuals of different generational cohorts. The Individualism cohort demonstrated the most negative perception of the positioning among the cohorts tested; the Post 1992 cohort perceived the positioning more negatively than the Lost Decade cohort; the Lost Decade cohort is the one with the most positive perception of the positioning among the cohorts tested.
\end{abstract}

Originality/value - The research evaluated in an unprecedented way if there are differences in the perception of the brand positioning of a HEI among the generational cohorts. The results contribute to the discussion of the characteristics of generational cohorts in Brazil and the impact that the generational differences may have on perceptions of brand positioning.

Keywords - Positioning, brand, generational cohorts, HEI, higher education
Received on

06/26/2018

Approved on

$01 / 16 / 2019$

Responsible editor:

Prof. Dr. Susana Costa e Silva

Evaluation process:

Double Blind Review

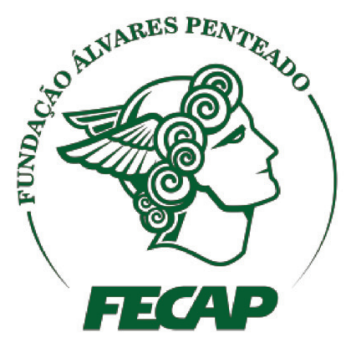

Review of Business Management 


\section{Introduction}

The description of the world in generational terms is a relatively modern phenomenon, reflecting changes in social structures caused by the democratization, industrialization, and technological advances experienced in the last few decades. These transformations have affected the awareness of time passing and it is necessary to find new ways to describe the narratives of social phenomena. Generations are used for the purpose of periodizing, as a way of ordering history, by locating phenomena in a bigger space-time (White, 2013).

The interest in studying generational cohorts lies in the alleged differences that exist between cohorts and the influence of those differences in social, professional, productive, and consumption relations. The differences might be expressive in several situations of specific interest in the marketing area and their potential impact on market and consumer behavior phenomena is noted by marketing researchers (Motta \& Schewe, 2008). In situations where the strategic marketing decision maker belongs to a different cohort from the target consumer of the organization, potential differences among generational cohorts might lead to dissociation between what is intended to be communicated by the organization and what is understood by the target consumer. In these circumstances, the same marketing action might be understood in a different manner by individuals from different generational cohorts, causing inefficiency of the marketing mix, a waste of organizational resources, failure to implement strategic definitions, and, consequently, damage to the brand positioning. Therefore, it is important to identify the differences between generational cohorts and how those differences are reflected in strategic marketing decisions and in perceptions of the marketing mix.

Studies have sought to understand generational cohorts as segmentation strategy (Fernádez-Dúran, 2015; Ikeda, Camponar, \& Pereira, 2008; Ikeda \& Feitosa, 2011; Noble \& Schewe, 2003; Schewe \& Meredith, 2004;), consumer behavior of different generational cohorts (Eastman \& Liu, 2012; Noble, Haytko \& Phillips, 2009; Pentecost \& Andrews, 2010; Youg \& Hinely, 2012)attitudes and impulse buying, and differences in the marketing decision process between individuals from different generational cohorts (Motta \& Schewe, 2008) little empirical evidence exists to support the validity of the concept. The goal of the current study was twofold: (1. However, until now, there has been a lack of empirical studies performed in order to verify if there is a difference between generational cohorts in perceptions of brand positioning.

Multi-method research was performed, using a qualitative and quantitative approach, where the object of study was the State University of Rio Grande do Sul (Universidade Estadual do Rio Grande do Sul - UERGS, in Portuguese), and which aimed to answer the following question: how do different Brazilian generational cohorts directly related to UERGS perceive the brand positioning of the university? Although some relationships tested in the research have been previously analyzed in marketing studies, the contribution lies in the tests performed, relating the proposed constructs in a unique way, i.e. brand positioning and generational cohorts.

Despite the social and economic importance of the higher education market in Brazil, the area requires studies on positioning and, consequently, debates, data collection, and analysis regarding the positioning of higher education institutions. Thus, the study presents a contribution to the theory of positioning in the context of higher education. Another contribution of the research involves cohort comparisons. Generational cohorts have been investigated separately and comparing cohorts has been the focus of a limited number of studies (Carpenter, Moore, Doherty \& Alexander, 2012)as a result of the increasingly globalized marketplace, researchers suggest that consumers within individual countries are becoming more culturally heterogeneous. Consequently, M. 
Cleveland and J. Laroche (2007. Acculturation to the global consumer culture: Scale development and research paradigm. Journal of Business Research, 60, 249-259. The classification of cohorts for the Brazilian context is also relevant, due to the size and relevance of the consumer market of Brazil and its social, historical, and cultural particularities.

The article is structured as follows. In the next section, the theoretical framework is presented, followed by the conceptual model and proposed study hypotheses. Then the study method and results of the research are presented. Finally, the article presents a discussion of the results, the study limitations, and the managerial implications of the research findings.

\section{Theoretical Framework and Study Hypotheses}

\section{I Brand Positioning in Higher Education Institutions}

Higher education is classified as a service sector activity (Alwi \& Kitchen, 2014; HemsleyBrown \& Oplatka, 2006). Despite the context of higher education being distinctive and presenting singularities, analysis models developed specially for this field are scarce (Hemsley-Brown \& Oplatka, 2006). In this context, students of higher education institutions are considered as direct receivers of the educational services and, therefore, as consumers or clients, especially for the application of marketing theories developed in a distinct context of services or production (Pinar, Trapp, Girard, \& Boyt, 2011).

In higher education, the service is characterized as being a process with numerous points of contact between the service supplier and client and with numerous service encounters. Points of contact and service encounters have a potential impact on the student's experience and, ultimately, on the brand, since it is designed based on the overall experience and each service encounter contributes positively or negatively to the experience. At universities, the overall experience is built up by the sum of experiences with core services and supplementary services. Classroom lectures and discussions, assignments, academic guidance, and research project supervision are considered core services. Complementary services are application processes, the payment of fees, campus facilities, and sports, among others (Pinar, Trapp, Girard, \& Boyt, 2011).

Higher education services have the peculiarity of benefiting multiple stakeholders. University students, departments and faculty members (professors and employees), former students, supporting members, employees, and managers of public and private organizations might be considered stakeholders, as well as the interest groups of those organizations, the State, accreditors, and the community in general (Aspara, Aula, Tienari, \& Tikkanen, 2014; Curtis, Abratt, \& Minor, 2009; Hemsley-Brown \& Goonawardana, 2007).

The brand in higher education enables the consolidation of outside and inside public perceptions about the education institution and its services. A university brand represents the perceptions and feelings of its stakeholders in relation to the institution (Rauschnabel, Krey, Babin, \& Ivens, 2016). Curtis, Abratt, and Minor (2009) state that brand is considered one of the most important assets of educational organizations. According to the authors, the characteristics of educational services increase this importance, especially intangibility and inseparability between production and consumption. As higher education is an intangible service, there is no possibility of previous experience or testing the service and the brand image works as an important decision criteria.

At education institutions, the brand affects specific questions for the success of the activity, such as capturing and retaining qualified professors and employees, reducing staff turnover, increasing productivity, attracting students and donations, resources, and fund raising (Alwi \& Kitchen, 2014; Robertson \& Khatibi, 2013; Hemsley- 
Brown \& Goonawardana, 2007)focusing on cognitive and affective brand attributes in the context of business schools. While previous research on university or institutional branding has studied these elements separately via cognitive (e.g., service or educational quality attributes. The brand may also be seen as a promise of expected benefits and it is used to distinguish the products or services of a certain organization in relation to those of competitors (Liu, Chapleo, Ko, \& Ngugi, 2015; Shams, 2015).

Brand positioning is the act of establishing the offer and the product image, seeking to occupy a distinct place in the mind of the consumer, using as a reference other market competitors (Fuchs \& Diamantopoulos, 2010; Wang, 2016) differentiation, and credibility, while controlling for brand-specific, product category-specific, and socio-demographic influences. The results show that the type of positioning strategy used affects the positioning success of a brand. More specifically, the study confirms normative arguments about the overall relative effectiveness of main positioning strategies by revealing that benefit-based positioning and surrogate (user. In conceptual terms, brand positioning resembles the brand image (Fuchs \& Diamantopoulos, 2010). The image is the concept attributed by the consumer to a brand, the result of individual consumer interpretation. Interpretation is a subjective and perceptual phenomenon, which can be rational or emotional, since each individual may interpret information in a different way according to their beliefs, thoughts, feelings, and impressions (Fuchs \& Diamantopoulos, 2010). Brand image and, consequently, brand positioning, relates to the perceptions and impressions stored in the memory of individuals, shared by members of a culture or subculture. It is the result of a mental map shaped by previous ideas, feelings, and experiences of individuals with the organization (Alwi \& Kitchen, 2014)focusing on cognitive and affective brand attributes in the context of business schools. While previous research on university or institutional branding has studied these elements separately via cognitive (e.g., service or educational quality attributes.

\subsection{Personal Values and Generational Cohorts}

Personal values are beliefs that guide the concept of the individual self. They are related to desired final states or manners of conduct (Rokeach, 1973). Considered relatively longlasting, they go beyond specific situations, remaining stable over the course of time (Rokeach, 1973; Schwartz, 1994). Personal values are considered predictors of human behavior in that they are the basis of individual models and criteria of conduct and they guide the selection or evaluation of behaviors, people, and events (Schwartz, 1994; Tang, Wang, \& Zhang, 2017). Therefore, human behaviors are the result of personal values and attitudes expressed by individuals (Motta \& Schewe, 2008).

Antecedents of personal values might be attributed to society, culture, and its social institutions (Noble \& Schewe, 2003; Schwartz, 1994). Values are formed through the socialization process, which occurs at micro and macro levels. Socialization at the micro level occurs at an individual level and is the result of modeling, support, and other types of social interactions. Socialization at the macro level occurs in the social field, from experiences in the political and social environment that influence the formation of beliefs, values, and attitudes of individuals (Noble \& Schewe, 2003).

Experiences of certain historical and social events result, also, in the formation of a connecting component among individuals, identifying that collective and its Zeitgeist, the spirit of the era that collective belongs to (Biggs, 2007; White, 2013). Historical events act as a "crystallization agent" of the group of individuals, in a process where the private conscience is shaped by social experiences. According to Biggs (2007), those moments result in the development of a generational conscience, resulting in a group that knows itself and behaves based on a common identity, called a generational cohort. 
Generational cohorts are defined as a range of individuals born during the same interval of time and who experience similar external events at the end of their teenage years and the beginning of adulthood (Fernández-Dúran, 2015; Ikeda, Campomar, \& Pereira, 2008; Motta \& Schewe, 2008; Noble \& Schewe, 2003), which occurs between around 17 and 23 years old (FernándezDurán, 2015). As a result of socialization at the macro level, individuals of the same generational cohort present similar values, belief systems, attitudes, and behaviors (Fernández-Durán, 2015; Gao, Zhang, \& Huang, 2017; Ikeda, Campomar, \& Pereira, 2008; Motta \& Schewe, 2008).

According to Gao, Zhang, and Huang (2017), generational cohorts might be considered a type of national subculture, in that they hold a set of common values, shaped by the social and economic events of a specific historical moment, occurring during a certain period of the individual cycle of life. As a result, differences among cultures, countries, and histories may shape different generational cohorts in each country. Fernández-Durán (2015) proposes that external events responsible for defining the personal values of individuals from generational cohorts are important events in a country's history in the areas of economics, politics, culture, nature, and technology. Along these lines, proposals of specific classifications for generational cohorts are identified in Brazil (Ikeda, Campomar, \& Pereira, 2008; Ikeda \& Feitosa, 2011; Motta \& Schewe, 2008), Mexico (Fernández-Durán, 2015), and China (Gao, Zhang, \& Huang, 2017; Tang, Wang, \& Zhang, 2017). Table 1 presents the generational cohorts proposed for the Brazilian context.

Table 1

Generational Cohorts of the Brazilian context

\begin{tabular}{|c|c|c|c|}
\hline Generation & Year of birth & Relevant external events & Main characteristics \\
\hline Optimism & $1937-1950$ & $\begin{array}{l}\text { Suicide of President } \\
\text { Vargas, election of } \\
\text { President Kubischek }\end{array}$ & $\begin{array}{l}\text { Nationalism, nostalgia, and sentimentality. Rejection of } \\
\text { disorder, acceptance of calculated risk, self-sufficiency, and } \\
\text { valorization of the organizational hierarchy. }\end{array}$ \\
\hline Iron Years & $1951-1962$ & $\begin{array}{l}\text { Military Dictatorial } \\
\text { Regime, social crisis, } \\
\text { Institutional Act } 5\end{array}$ & $\begin{array}{l}\text { They avoid uncertainty and are characterized by belligerence, } \\
\text { solidarity, alienation, silence, monopolistic thought, and the } \\
\text { pursuit of safety. Valorization of formal education. }\end{array}$ \\
\hline Lost Decade & $1963-1974$ & $\begin{array}{l}\text { Amnesty for activists, } \\
\text { end of economic growth. }\end{array}$ & $\begin{array}{l}\text { Materialists, ambitious, seek immediate feedback. More } \\
\text { pessimistic than the other generations, they believe that } \\
\text { nothing is good and that the future is uncertain. Negligence } \\
\text { in relation to future generations, they believe that conflict is } \\
\text { inevitable and their decisions are guided by personal benefits. }\end{array}$ \\
\hline Individualism & $1975-1992$ & $\begin{array}{l}\text { Government crisis, } \\
\text { impeachment of } \\
\text { President Collor, change } \\
\text { of the national currency }\end{array}$ & $\begin{array}{l}\text { Individualists, self-sufficient, consumerists, pragmatists, with } \\
\text { no commitment to maintaining social patterns, they believe } \\
\text { that nothing is for life. They are familiar with the internet, } \\
\text { using it to arrange social gatherings and create a global } \\
\text { community. }\end{array}$ \\
\hline Post 1992 & $1993-$ & $\begin{array}{l}\text { Stable economy, wide use } \\
\text { of technology, protests in } \\
\text { 2013, impeachment of } \\
\text { President Rousseff. }\end{array}$ & $\begin{array}{l}\text { Digital generation that uses more than one digital media } \\
\text { at the same time and values interactive communication. A } \\
\text { little worried about hierarchy and individualists. They seek } \\
\text { identification with brands that offer substance. They live in } \\
\text { a globalized environment, with increased buying power and } \\
\text { international trade and ease of access to higher education } \\
\text { through the policy of quotas, state funding, and expansion of } \\
\text { federal universities. }\end{array}$ \\
\hline
\end{tabular}

Note. Source. Adapted from Ikeda and Feitosa (2011), Ikeda, Campomar, and Pereira (2008), Schewe and Meredith (2004), and Motta and Schewe (2008). 


\subsection{Conceptual Model and Study Hypotheses}

The conceptual model proposed for the research is shown in Figure 1 and presents the interrelations among the concepts discussed in the theoretical framework. The model is based on the relationships among generational cohorts, personal values, and brand positioning.

H3

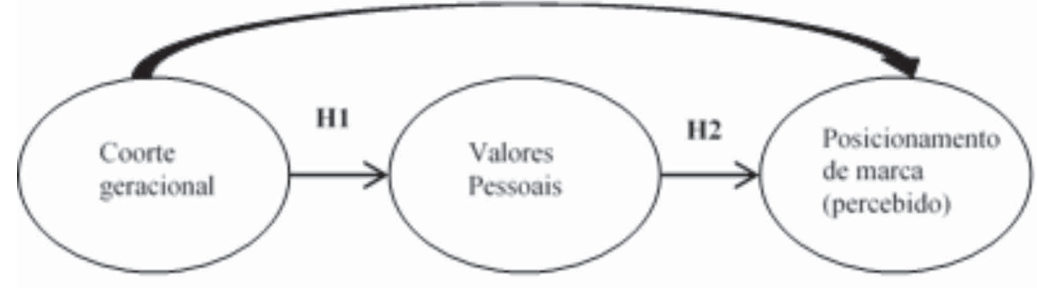

Figure 1. Conceptual research model proposed

Generational cohorts are groups of individuals at about the same age that share experiences of relevant external events during the end of their teenage years and the beginning of adulthood, resulting in the formation of a common identity for that group. As a result of that common identity, the group of individuals shares values and belief systems and presents similar desires, preferences, behaviors, and attitudes (Fernández-Durán, 2015; Gao, Zhang, \& Huang, 2017; Ikeda, Campomar, \& Pereira, 2008; Noble \& Schewe, 2003; Weiss \& Lang, 2009). Due to the socialization process occurring at the individual and social level, individuals that have lived in similar environments and experienced similar historical events at the end of adolescence and beginning of adulthood, in other words, individuals of the same generational cohort, must present similarities in their system of values, even considering the influences of socialization at the individual level. Noble and Schewe (2003) argue that personal values may be able to distinguish individuals at a similar age that have experienced similar macro socialization processes. Therefore, the following study hypothesis is suggested:

H1: Individuals of the same generational cohort will share the same personal values.

Personal values influence perceptions of brand positioning, considering the relationships among personal values, benefits, attributes, and brand positioning. Brand positioning occurs through attributes that allow consumers to make distinctions and comparisons between the offers of competitors in a specific market (Lee \& Liao, 2009). The consumer's needs are guided by higherorder personal values, such as happiness, safety, a sense of belonging, and achievement. Those needs are met through benefits, communicated through attributes. Therefore, the meaning attributed by the consumer to a product is influenced by the values of the consumer, establishing a sequence of connections with benefits, attributes, and, consequently, brand positioning.

Based on the above, the following study hypothesis is suggested:

\section{H2: Personal Values influence the perception of UERGS's brand positioning.}

A shared socialization process at the macro level results in the formation of a system of common values and beliefs and in similar desires, preferences, behaviors, and attitudes among individuals of the same generational cohort (Fernández-Durán, 2015; Gao, Zhang, \& Huang, 2017; Weiss \& Lang, 2009; Ikeda, Campomar, \& Pereira, 2008; Motta \& Schewe, 2008; Noble \& Schewe, 2003). Perception of the brand positioning is a result of information interpretation and experiences related to the 
brand and this interpretation is a subjective and perceptual phenomenon, based on beliefs, thoughts, feelings, and impressions (Fuchs \& Diamantopoulos, 2010). Brand positioning results from perceptions and impressions stored in the memory of individuals, shared by members of a culture or subculture (Alwi \& Kitchen, 2014)focusing on cognitive and affective brand attributes in the context of business schools. While previous research on university or institutional branding has studied these elements separately via cognitive (e.g., service or educational quality attributes, where generational cohort is considered a type of national subculture (Gao, Zhang, \& Huang, 2017).

This study assumes individuals of the same generational cohort have a similar perception regarding brand positioning, since they share the same range of personal values and beliefs. The range of personal values is an important factor in determining the interpretation of information and the perception regarding brand positioning. Based on these arguments, the following study hypothesis is suggested:

H3: Individuals of different generational cohorts will have distinct perceptions in relation to UERGS's brand positioning.

\section{Method}

To achieve the goals, a multimethod explanatory study was performed using a qualitative and quantitative approach. The qualitative stage aimed to validate brand positioning and personal values scales, besides expanding and improving the understanding of the studied topics. In this stage, semi structured interviews were carried out with professors, technical and administrative support personnel, and students from UERGS: 6 students, 6 professors, and 1 employee from the communications department of the university. The respondents were questioned about cognitive and affective attributes of UERGS and higher education institutions and the results contributed to the construction of the quantitative instrument.
The second phase is characterized as a survey. Data were collected through printed selfcompletion anonymous structured questionnaires. For the analysis of the collected data, the IBM SPSS Statistics version 21 and Microsoft Excel 2013 softwares were used.

\section{I Characterization of the Organization Studied}

UERGS is the organization that is the object of the study. Founded in 2001, it is characterized as a public state university located over multi campuses, with its main administration in Porto Alegre/RS and units located in 24 different cities of the state of Rio Grande do Sul. UERGS has around 4.3 thousand students enrolled in graduation and post-graduation courses in the areas of Human Sciences, Life and Environmental Sciences, Exact Sciences, and Engineering.

The strategic marketing positioning of UERGS is based on the institution's mission, which is related to promoting regional development (UERGS, 2010). Institutional communications have emphasized attributes such as the quality of education, highlighting the scores obtained in ranks of HEI evaluations; there being no tuition fees; the profile of course offerings, geared towards to regional demands; and the quality of professors.

In the last few years, UERGS has engaged in annual publicity campaigns for student enrollment. The campaigns cover the whole state of Rio Grande do Sul, with an emphasis on electronic media (Facebook, Twitter, YouTube, and the institutional website on the internet), due to the budgetary and financial restrictions experienced by the university. The campaigns generally use students from the university itself, as well as the participation of professors. Word-ofmouth marketing and releasing institutional news are communication strategies of the institution's brand.

In the period when the research was applied, the marketing campaign was based on student interviews, reporting real positive 
experiences of international academic exchanges and placement of those students in the job market, emphasizing the quality of education of the university. In the same period, a campaign for UERGS's 15th anniversary was developed using cases of research, education, and extension at the university with a positive impact on the development of the regions of UERGS.

\subsection{Population and Sample}

The population of the study is formed of 4,806 individuals: 467 personnel, including 7 managers, 262 professors, and 198 technical and administrative support personnel, and 4,339 students of the graduation and post-graduation courses of UERGS. The study population was defined considering that higher education is an activity type of the service sector (Alwi \&
Kitchen, 2014; Hemsley-Brown \& Oplatka, 2006), with numerous points of contact between the supplier and service clients and numerous service encounters (Pinar, Trapp, Girard, \& Boyt, 2011). Because it is an explanatory study, only a portion of the stakeholders of the organization was chosen. The population was selected based on the understanding that students and staff are responsible for the production and creation of value in higher education services, and are decisive for the image and brand positioning (Chun \& Davies, 2006; Hemsley-Brown \& Oplatka, 2006). Individuals from these populations were directly exposed to the brand communication efforts carried out by UERGS and experienced service encounters and value creation at the institution.

The sample characteristics are presented in Table 1.

Table 1

\section{Sample Characterization}

\begin{tabular}{|c|c|c|c|c|c|c|}
\hline & \multicolumn{2}{|c|}{ Students } & \multicolumn{2}{|c|}{ Staff* } & \multicolumn{2}{|c|}{ Total } \\
\hline & Frequency & Percentage & Frequency & Percentage & Frequency & Percentage \\
\hline \multicolumn{7}{|l|}{ Generation } \\
\hline Optimism & 0 & $0.00 \%$ & 1 & $0.94 \%$ & 1 & $0.37 \%$ \\
\hline Iron Years & 4 & $2.40 \%$ & 14 & $13.21 \%$ & 18 & $6.59 \%$ \\
\hline Lost Decade & 15 & $8.98 \%$ & 19 & $17.92 \%$ & 34 & $12.45 \%$ \\
\hline Individualism & 54 & $32.33 \%$ & 70 & $66.04 \%$ & 124 & $45.42 \%$ \\
\hline Post 1992 & 94 & $56.29 \%$ & 2 & $1.89 \%$ & 96 & $35.17 \%$ \\
\hline \multicolumn{7}{|l|}{ Gender } \\
\hline Female & 107 & $64.07 \%$ & 63 & $59.43 \%$ & 170 & $62.27 \%$ \\
\hline Male & 60 & $35.93 \%$ & 43 & $40.57 \%$ & 103 & $37.73 \%$ \\
\hline \multicolumn{7}{|c|}{ HEI chosen for comparison } \\
\hline UFRGS & 63 & $37.73 \%$ & 53 & $50.00 \%$ & 116 & $42.49 \%$ \\
\hline UFSM & 35 & $20.96 \%$ & 27 & $25.47 \%$ & 62 & $22.71 \%$ \\
\hline PUC/RS & 15 & $8.98 \%$ & 14 & $13.21 \%$ & 29 & $10.62 \%$ \\
\hline UNISINOS & 14 & $8.38 \%$ & 1 & $0.94 \%$ & 15 & $5.50 \%$ \\
\hline IF & 40 & $23.95 \%$ & 11 & $10.38 \%$ & 51 & $18.68 \%$ \\
\hline Total & 167 & $61.17 \%$ & 106 & $38.83 \%$ & 273 & $100.00 \%$ \\
\hline
\end{tabular}

Note: Staff is composed of managers, professors, and technical and administrative support personnel.

The sample is not representative and defined by convenience and by quotas. 350 questionnaires were sent to 12 different campuses seeking to maintain the proportionality of the sample in relation to the distribution of the population in the campuses. 323 questionnaires came back, of which 50 were eliminated due to completion problems, resulting in a final sample of 273 valid questionnaires. 


\subsection{Measurement}

The scale for measuring brand positioning was developed from the attributes proposed by Alwi and Kitchen (2014) in research on the image of the corporative brands of higher education institutions and from the attributes of the research of Gray, Fam, and Llanes (2003) on the value attributed by students of higher education institutions and its implications for universities' brand positioning. To verify brand positioning perceptions, the attributes were divided into cognitive and affective attributes, following what was proposed by Alwi and Kitchen (2014).

Cognitive attributes were measured with a five-point Likert scale, in which " 1 " meant "fully agree" and "5" meant "fully disagree". Affective attributes were evaluated through a semantic differential scale: on the left end, next to the number 1 , the word that defined the affective variable was written (for example: concerned) and on the right end of the scale, next to the number 5 , the antonym of the variable was written (for example: unconcerned).

The scale of personal values used in the study follows what was proposed by Noble and Schewe (2003), which was chosen since it was developed for the identification of generational cohorts, based on the List of Values (LOV) of Kahle (1983) and the Rokeach Scale of Value (1973). For the personal values scale, a nine-point Likert scale was used in an unbalanced form, with scores from " 1 " - it is unimportant to me - to "9" - it is very important to me, according to what was suggested by Noble and Schewe (2003).

The three scales used in the research were originally in English. They were translated into Portuguese using the back-translation technique and were evaluated by two experts, who were doctor professors in Marketing, and evaluated in the qualitative stage. The final scales used were formed of 25 cognitive attributes, 17 affective attributes, and 26 personal values. The instrument was tested in a pre-test with a subgroup of the sample.

Considering that the brand positioning is always relative to the other organizations existing in the market, the respondents were required to evaluate UERGS and chose for the evaluation one of five options of higher education institutions presented in the research instrument. The questionnaire was elaborated in order to include identical scales for evaluating UERGS and the chosen HEI, placed side by side in the questionnaire. The five HEIs presented were selected from the rank of the General Index of Courses in 2016 of the National Office of Educational Studies and Research Anísio Teixeira (INEP, 2016). The GIC is an indicator of quality proposed and measured by the federal government and published annually, which evaluates HEIs through the results of their graduation and stricto sensu post-graduation courses (INEP, 2016). Table 2 presents the characterization of the HEIs evaluated.

Table 2

\section{Characterization of HEIs for comparison}

\begin{tabular}{lccccc}
\hline HEI & Profile & Campuses (RS) & $\begin{array}{c}\text { Number of } \\
\text { Students }\end{array}$ & $\begin{array}{c}\text { Time in } \\
\text { operation }\end{array}$ & $\begin{array}{c}\text { GIC } \\
\text { (range) }\end{array}$ \\
\hline UERGS & Public State & Porto Alegre and 23 cities & 4,5 thousand & 17 years & 4 \\
UFRGS & Public Federal & Capital and northern coast & 47.3 thousand & 123 years & 5 \\
UFSM & Public Federal & Santa Maria and northern-central region & 4,7 thousand & 58 years & 4 \\
UNISINOS & Private & Porto Alegre and São Leopoldo & 31 thousand & 48 years & 4 \\
PUC/RS & Private & Porto Alegre and Uruguaiana & 25.2 thousand & 87 years & 4 \\
IF & Public Federal & Porto Alegre and 49 cities & 52 thousand & 10 years & 4 \\
\hline
\end{tabular}

HEIs from the state of Rio Grande do Sul with the greatest "continuous GIC" indicators were selected, removing the Federal University of Health Sciences, because its area of activities is different from that of UERGS. All the HEIs for comparison offer graduation and post-graduation courses in the areas of activity of UERGS. 


\section{Results}

\section{I Attributes for evaluating brand positioning}

The attributes for evaluating brand positioning were subjected to factor analysis with Varimax rotation, using the data obtained in the evaluation of UERGS $(n=273)$. The factor structure for the cognitive and affective attributes of the UERGS evaluation is presented in Table 3.

Table 3

Items and final variables of cognitive and affective attribute measurements

\begin{tabular}{|c|c|c|c|c|}
\hline Dimension & Item & $\begin{array}{l}\text { Cronbach's } \\
\text { Alpha }\end{array}$ & Variable & Factor \\
\hline \multirow[t]{17}{*}{ Cognitive } & Lecturers & 0.925 & The professors' explanations are clear to understand & 0.846 \\
\hline & & & $\begin{array}{l}\text { The communications between professors and students are } \\
\text { clear }\end{array}$ & 0.763 \\
\hline & & & The feedback between teachers and students is appropriate & 0.792 \\
\hline & & & The professors are experts in their areas & 0.796 \\
\hline & & & The professors are well informed & 0.832 \\
\hline & & & The professors treat the students respectfully & 0.821 \\
\hline & & & The professors are available outside the classroom & 0.797 \\
\hline & & & The university has modern processes and administrative tasks & 0.775 \\
\hline & Administration & 0.793 & The university has proper administrative procedures & 0.815 \\
\hline & & & The administration of the university/campus is accessible & 0.533 \\
\hline & & & The administrative processes are agile and efficient & 0.838 \\
\hline & & & The physical facilities are modern and up to date & 0.779 \\
\hline & & 0.806 & The physical facilities are visually attractive & 0.768 \\
\hline & Physical Facilities & & The physical facilities are easy to access & 0.642 \\
\hline & & & The students have good salary expectations after graduation & 0.879 \\
\hline & $\begin{array}{l}\text { Graduate Career } \\
\text { Prospects }\end{array}$ & 0.796 & Employers have a positive view of the university's graduates & 0.638 \\
\hline & & & $\begin{array}{l}\text { The university's graduates have good career prospects after the } \\
\text { graduation }\end{array}$ & 0.847 \\
\hline \multirow[t]{14}{*}{ Affective } & Empathy & 0.925 & Concerned & 0.696 \\
\hline & & & Agreeable & 0.764 \\
\hline & & & Encouraging & 0.797 \\
\hline & & & Supportive & 0.691 \\
\hline & & & Trustworthy & 0.712 \\
\hline & & & Innovative & 0.701 \\
\hline & & & Creative & 0.743 \\
\hline & & & Motivating & 0.787 \\
\hline & & & Fulfilling & 0.784 \\
\hline & & & Corporate & 0.645 \\
\hline & & & Hard working & 0.763 \\
\hline & Prestige & 0.623 & Elitist & 0.840 \\
\hline & & & Sophisticated & 0.617 \\
\hline & & & Exclusive & 0.736 \\
\hline
\end{tabular}

Note: Cronbach's alpha of cognitive attributes scale $=0.866$; Cronbach's alpha of affective attributes scale $=0.910$. 
After the factor analysis, a set of 31 attributes of the HEI brand positioning evaluation was obtained, 17 cognitive and 14 affective. The cognitive attributes were grouped into 4 dimensions: Lecturers (7 attributes), Administration ( 4 attributes), Physical Facilities (3 attributes), and Graduate Career Prospects (3 attributes). The four factors obtained were based on the scales used as a reference for this research (Alwi \& Kitchen, 2014; Gray, Fam, \& Llanes, 2003). The affective attributes were grouped into 2 dimensions: Empathy (11 attributes) and Prestige (3 attributes). The empathy dimension encompasses three dimensions of the original scale of Alwi and Kitchen (2014): Empathy, Adventurous, and Competence. The prestige dimension is similar to the dimension called "Prestigious" by Alwi and Kitchen (2014).

\subsection{Personal Values}

The analysis of the personal values scale data was performed through statistical factor analysis with Varimax rotation.15 factors were obtained, grouped in two dimensions: Selfrelationships and Relationships with the Social Environment (Table 4).

Table 4

Factorial Structure of the Personal Values Scale

\begin{tabular}{llll}
\hline Dimension & Cronbach Alpha & Variable & Factor \\
\hline Self-Relationships & 0.972 & Being true to themselves & 0.894 \\
& & 0.897 & 0.842 \\
& Believing in their own value & 0.811 \\
& Having integrity & 0.816 \\
& Having confidence & 0.759 \\
Relationships with the & 0.97 & Having close and supportive friends & 0.782 \\
social environment & & Being part of a group and feeling supported by it & 0.716 \\
& Aspiring to progress & 0.713 \\
& Wishing equal opportunities for everybody & 0.736 \\
& Protecting the environment & 0.755 \\
& Living without financial worries & 0.727 \\
& Protecting their public image & 0.776 \\
& Having exciting experiences & 0.800 \\
& Experiencing stimulation and excitement & 0.747 \\
& Believing that the present matters more than the past &
\end{tabular}

Note. Reference: Cronbach's Alpha $=0.978 ;$ Kaiser-Meyer-Olkin Measure $=s i g<0.05$.

The original scale of Noble and Schewe (2003) has 7 dimensions. From comparing the results of the research with the original scale, it is verified that the dimension of the research called "Self-relationships" is related to the "Self-Respect" dimension and "Relationships with the social environment" encompasses the other dimensions proposed by the authors.

\subsection{Hypothesis Tests}

We sought to identify the differences between the generational cohorts through the factor analysis, using personal values as a group parameter. The analysis aimed to verify research hypothesis H1: Individuals of the same generational cohort will share the same 
personal values. The analysis considered the complete sample as a parameter $(n=273)$, without differentiating between individuals from the group of students and staff. The results in Table 5 show high Wilks Lambda values close to 1, meaning an absence of differences between groups.

Table 5

\section{Wilks Lambda}

\begin{tabular}{ccccc}
\hline $\begin{array}{c}\text { Functions } \\
\text { test }\end{array}$ & $\begin{array}{c}\text { Wilks } \\
\text { Lambda }\end{array}$ & Chi-squared & DF & Sig. \\
\hline 1 to 2 & 0,894 & 26,798 & 8 & 0,001 \\
2 & 0,996 & 1,061 & 3 & 0,787 \\
\hline
\end{tabular}

The canonical discriminant functions obtained in the analysis did not allow for the identification of the grouping from the personal values. The results obtained in the discriminant analysis did not allow for a relationship between generational cohorts and personal values to be identified, leading to the rejection of hypothesis H1. The results of the discriminant analysis did not allow for hypothesis $\mathrm{H} 2$ to be tested.

To test research hypothesis H3: Individuals of different generational cohorts will have different perceptions in relation to the brand positioning of UERGS, the sample was stratified by year of birth, according to the classification presented in Table 1 . The data collected enabled the analysis of individuals from 3 generational cohorts: Lost Decade, Individualism, and Post 1992. The generational cohorts Optimism $(n=1)$ and Iron Years $(n=18)$ were not considered in the analysis, since the sample of individuals from those generational cohorts did not reach the minimum quantity necessary for the statistical procedure proposed.

To evaluate the perceptions of positioning, the difference in the averages of the research attributes evaluation obtained by UERGS and the comparison HEIs was calculated. The difference in average was obtained by deducting the average obtained in the evaluation of UERGS's attributes from the average obtained in the evaluation of each of the comparison HEIs' attributes. The ANOVA test and Dunnett C post hoc test were performed to find statistically relevant (significance level of $5 \%$ ) differences in the averages between the 3 generational cohorts compared. Table 6 presents the statistically relevant differences in average from the test carried out. 
Table 6

Statistically relevant differences in average between generational cohorts in the positioning variables - Dunnett C Test

\begin{tabular}{|c|c|c|c|c|c|}
\hline $\begin{array}{l}\text { Generational } \\
\text { Cohorts } \\
\text { Compared }\end{array}$ & Type & Dimension & Variable & Comparison & $\begin{array}{l}\text { Difference* } \\
\text { in Averages }\end{array}$ \\
\hline \multirow{7}{*}{$\begin{array}{l}\text { Lost Decade } \\
\text { and Post } \\
1992\end{array}$} & Affective & Empathy & Pleasant & PUC/RS & 0.72 \\
\hline & Cognitive & Administration & $\begin{array}{l}\text { The university has proper administrative } \\
\text { procedures }\end{array}$ & IF & -0.59 \\
\hline & & Lecturers & $\begin{array}{l}\text { The professors' explanations are clear to } \\
\text { understand }\end{array}$ & UFSM & -1.06 \\
\hline & & & The professors are well informed & UNISINOS & -1 \\
\hline & & & The professors treat the students respectfully & UFRGS & 0.78 \\
\hline & & $\begin{array}{l}\text { Graduate Career } \\
\text { Prospects }\end{array}$ & $\begin{array}{l}\text { The students have good salary expectations } \\
\text { after graduation }\end{array}$ & UFRGS & -0.83 \\
\hline & & & $\begin{array}{l}\text { The graduates have good career prospects } \\
\text { after graduation }\end{array}$ & UFRGS & -0.68 \\
\hline \multirow{4}{*}{$\begin{array}{l}\text { Lost } \\
\text { Decade and } \\
\text { Individualism }\end{array}$} & Cognitive & Lecturer & $\begin{array}{l}\text { The professors' explanations are clear to } \\
\text { understand }\end{array}$ & UFSM & -0.77 \\
\hline & & $\begin{array}{l}\text { Graduate Career } \\
\text { Prospects }\end{array}$ & $\begin{array}{l}\text { The students have good salary expectations } \\
\text { after graduation }\end{array}$ & IF & -0.65 \\
\hline & & & $\begin{array}{l}\text { The students have good salary expectations } \\
\text { after graduation }\end{array}$ & UFRGS & -0.83 \\
\hline & & & $\begin{array}{l}\text { The graduates have good career prospects } \\
\text { after graduation }\end{array}$ & UFRGS & -0.68 \\
\hline \multirow{4}{*}{$\begin{array}{l}\text { Post } \\
1992 \text { and } \\
\text { Individualism }\end{array}$} & Affective & Empathy & Trustworthy & UFRGS & -0.84 \\
\hline & & Motivating & UFRGS & -0.88 & \\
\hline & Cognitive & Lecturer & $\begin{array}{l}\text { The communication between professors and } \\
\text { students is clear }\end{array}$ & UFRGS & -0.73 \\
\hline & & $\begin{array}{l}\text { Graduate Career } \\
\text { Prospects }\end{array}$ & $\begin{array}{l}\text { The graduates have good career prospects } \\
\text { after graduation }\end{array}$ & UFRGS & -0.74 \\
\hline
\end{tabular}

* Significance level of $5 \%$.

Statistically relevant differences in averages were found in 15 cases, leading to the acceptance of hypothesis H3. The differences were identified in affective variables (3 cases) and in cognitive variables (12 cases). The comparison between the Lost Decade and Post 1992 cohorts found significant differences in averages in 7 attributes; in 4 attributes between the Lost Decade and Individualism cohorts; and in 4 attributes between the Post 1992 and Individualism cohorts.

\subsection{Discussion}

The study proposed three research hypotheses. The results of the discriminant analysis suggest that there is no relationship between the generational cohorts and personal values, leading to the rejection of research hypothesis $\mathrm{H} 1$ and making the testing of research hypothesis $\mathrm{H} 2$ impossible. The results found differ from the proposition of Fernández-Duran (2015) that individuals of the same generational cohort share the same personal values. The author researched Mexican generational cohorts and identified them successfully from personal values.

The results converge with the proposition of Motta and Schewe (2008) that the relationship between personal values and generational cohorts is not clear and not direct. According to the 
authors, generational cohorts are independent of the personal values system and the personal values system is neither necessary nor enough for their determination. Even considering that the identification and description of generational cohorts is based on shared relevant historical events, Motta and Schewe (2008) argue that different forces mould personal values and that relevant historical events represent only one of those forces. Noble and Schewe (2003) recommend considering that the possibility of personal values is too abstract as a variable for grouping individuals into generational cohorts.

The results of the research suggest that there is a difference in the perception of the brand positioning of UERGS between individuals of different generational cohorts, leading to the acceptance of research hypothesis H3. It was verified that: 1) the Individualism cohort showed the most negative perception of the brand positioning of UERGS among the cohorts tested;

2) the Post 1992 cohort perceived the brand positioning of UERGS more negatively than the Lost Decade cohort; 3) the Lost Decade cohort is the one with the most positive perception of the brand positioning of UERGS among the cohorts tested.

The differences found call for reflections regarding the characteristics of Brazilian cohorts. Studies that consider cohort classifications for the Brazilian context are scarce and the descriptions of Brazilian cohorts found in the academic literature emphasize characteristics of the historical and economic environment experienced by the individuals, connected to the shared relevant external events. Therefore, there is a reduced theoretical framework to compare the results obtained in the research. One of the results that may be compared to the previous literature relates to the Lost Decade cohort. This cohort is described by Motta and Schewe (2008) as being the most pessimistic of the Brazilian cohorts, composed of questioning individuals that believe that nothing can be good. Unlike the description in the literature, the research findings demonstrate that individuals of the Lost Decade cohort perceived the brand positioning of UERGS more positively than individuals of the other cohorts studied. It is possible that the pessimism of those individuals is highlighted in other areas and behaviors; however, it is verified that this characteristic does not apply to the perception of brand positioning in the present study.

The Post 1992 cohort is a new Brazilian cohort and there is a lack of descriptions in the academic literature and a lack of scientific studies that contribute to describing its characteristics, values, and habits. It is composed of individuals that were born in the digital era and personifies the changes that technology has caused in society, which are the implied differences in relation to individuals of the previous cohorts. However, there may be more speculation regarding the behavior and habits of these individuals than data support. In light of this gap, is it possible to seek in the descriptions of American cohorts' support to compare the data found in the present study? The Millennials cohort is composed of individuals born in the United States between 1990 and 2000, corresponding to the Brazilian Post 1992 cohort, and it is described by Brosdahl and Carpenter (2011) as the most optimistic cohort in US history. That description differs from the results obtained, which suggest that the individuals of the Lost Decade cohort are the most positive with regards to their perception of UERGS's brand positioning.

This comparison leads to a reflection on the use of American cohorts in research performed in different countries. In Brazil, the use of American cohorts is common in academic research in the Marketing area. However, for Schewe and Meredith (2004), the use of American cohorts on a global scale is questionable and not all countries' generations are identified in the USA, due to the role of shared relevant historical events in the formation of generations. Various authors reinforce the need to use specific cohort classifications for the context of each country (Fernández-Duran, 2015; Gao, Zhang, \& 
Huang 2017; Schewe \& Meredith, 2004). The results of the research might be an indication that Brazilian generational cohorts present different characteristics from American cohorts. Furthermore, it might be an indication that there is the need to deepen the study of Brazilian cohorts' characteristics.

The research presents the identification of relevant attributes for perceptions of the brand positioning of universities. 31 attributes evaluating the brand positioning of higher education institutions were identified, including cognitive and affective ones. The findings are aligned with what was proposed by Alwi and Kitchen (2014) and Rauschnabel, Krey, Babin, and Ivens (2016), indicating that the corporative image of higher education institutions and, consequently, their brand positioning, are formed from cognitive and affective attributes. However, the dimensions of affective attributes found in the research differ from the dimensions suggested by the authors, which, on the other hand, differed from the dimensions of affective attributes of earlier research. These results might indicate that affective attributes related to perceptions of image and brand positioning depend on the social and cultural context of the country where the HEI operates. For the record, the study of Alwi and Kitchen (2014) was performed in a HEI in Malaysia.

\section{Conclusions}

The study aimed to evaluate how different Brazilian generational cohorts that are directly related to the State University of Rio Grande do Sul - UERGS perceived the brand positioning of the university. The results suggest that there is a difference between cohorts, verified in the perceptions of affective and cognitive variables. Tests showed differences in the perceptions of attributes between all pairs of cohorts compared.

\section{I Theoretical Contribution}

The research evaluated in an unprecedented way the differences between generational cohorts in perceptions of the brand positioning of an HEI. The findings suggest that generational cohorts perceive brand positioning differently, thus presenting an important contribution to the single subject approach. The differences identified in this research had not been described so far, considering the lack of empirical studies jointly analyzing the brand positioning and generational cohort constructs and considering the classification of cohorts for the Brazilian context. The literature is scarce regarding the identification, characterization, and explanation of the differences between Brazilian generational groups, which makes comparisons with earlier studies difficult. The marketing area research performed in Brazil mostly uses generational cohorts identified for the American sociohistorical cultural context, which became questionable in light of the results obtained in the research.

The findings suggest that, in relation to the perceptions of the brand positioning, the generational cohorts present different characteristics from the ones reported in the literature. This discovery presents valuable contributions for advancing the theory of brand positioning and generational cohorts in that it contributes to uncovering characteristics not explored until now in the context of brand positioning.

\subsection{Managerial contributions}

It is important to consider the implications of the research findings. The differences between generational cohorts have a direct influence on marketing strategies, communication strategies, and the planning and operationalization of the marketing mix. The study provides support to institutions to refine the process of strategic positioning and brand positioning, resulting in positioning advantages in the market. Efforts and resources of the institution might be more efficiently used if the differences between the generational cohorts are known and considered in the planning and execution of the marketing 
mix, especially in the case of HEIs, whose target public and stakeholders are formed of individuals of different generations. Identifying and understanding the differences between generational cohorts will help managers to reach their target public with messages and appropriate content, thus increasing the effectiveness of communications.

The research identified the relevant cognitive and affective attributes for evaluating the image and brand positioning of higher education institutions. Knowing the range of relevant attributes for the perception of the brand positioning of HEIs allows institutions to center their marketing efforts on more efficient communication actions and make their services tangible to stakeholders, resulting in a more concrete vision of the organization and of the services offered.

\section{$5 \cdot 3$ Limitations and suggestions for new studies}

The study presents limitations related to the uniqueness of the subject, which sought to verify the differences between the generational groups in their perceptions of the brand positioning, by combining in the same study two important concepts never before used together. Since it is a study applied in only one institution, it needs to be reproduced in other HEIs for confirmatory purposes.

Another limitation concerns the public of the research, which covered only students and staff, and not the other stakeholders reported in the literature. The population chosen for the study, limited to a portion of the stakeholders with direct contact with the institution, may have influenced the results found. As a future proposal, research with the other categories of stakeholders that have contact with the brand, and with a randomly-selected sample is suggested, with greater statistical significance and that allows for more sophisticated analysis. Invariance analysis measures might be used to verify differences between groups.
The continuity of specific studies on generational cohorts in the Brazilian socio-cultural context is suggested. In future research, other variables may be considered in the theoretical model, such as gender, socio-economic class, and nature of the connection with the organization. Generational clusters for personal values were not found and it is suggested that the research is repeated, seeking to identify those clusters. The literature presents a variety of scales for personal values and different groups of values might be tested in future research. Finally, it is indicated that longitudinal studies be carried out to verify if the differences found are not a reflection of other factors, such as the phase in the life of the participants.

Acknowledgments: We acknowledge the contribution of Prof. Jorge Lengler in the research and in this manuscript.

\section{References}

Alwi, S. S. F., \& Kitchen, P. J. (2014). Projecting corporate brand image and behavioral response in business schools: Cognitive or affective brand attributes? Journal of Business Research, 67(11), 2324-2336.

Biggs, S. (2007). Thinking about generations: Conceptual positions and policy implications. Journal of Social Issues, 63(4), 695-711.

Brosdahl, D. J. C., \& Carpenter, J. M. (2011). Shopping orientations of US males: A generational cohort comparison. Journal of Retailing and Consumer Services, 18(6), 548-554.

Carpenter, J., Moore, M., Doherty, A. M., \& Alexander, N. (2012). Acculturation to the global consumer culture: A generational cohort comparison. Journal of Strategic Marketing, 20(5), 411-423. http://doi.org/10.1080/09652 54X.2012.671340

Chun, R., \& Davies, G. (2006). The Influence of Corporate Character on Customers and 
Employees: Exploring Similarities and Differences. Journal of the Academy of Marketing Science, 34(2), 138-146.

Curtis, T., Abratt, R., \& Minor, W. (2009). Corporate brand management in higher education: the case of ERAU. Journal of Product \& Brand Management, 18(6), 404-413.

Eastman, J. K., \& Liu, J. (2012). The impact of generational cohorts on status consumption: an exploratory look at generational cohort and demographics on status consumption. Journal of Consumer Marketing, 29(2), 93-102.

Fernández-Durán, J. J. (2015). Defining generational cohorts for marketing in Mexico. Journal of Business Research.

Fuchs, C., \& Diamantopoulos, A. (2010). Evaluating the effectiveness of brand-positioning strategies from a consumer perspective. European Journal of Marketing, 44(11/12), 1763-1786.

Gao, J., Zhang, C., \& Huang, Z. J. (2017). Chinese tourists' views of nature and natural landscape interpretation: a generational perspective. Journal of Sustainable Tourism, O(0), 1-17.

Gray, B. J., Fam, K. S., \& Llanes, V. a. (2003). Branding universities in Asian markets. Journal of Product \& Brand Management, 12(2), 108-120.

Hemsley-Brown, J., \& Goonawardana, S. (2007). Brand harmonization in the international higher education market. Journal of Business Research, 60(9), 942-948.

Hemsley-Brown, J., \& Oplatka, I. (2006). Universities in a competitive global marketplace: a systematic review of the literature on higher education marketing. International Journal of Public Sector Management, 19(4), 316-338.

Ikeda, A. A., Campomar, M. C., \& Pereira, B. de C. S. (2008). Uso de Coortes em Segmentação de Marketing. O\&S, 15(44), 25-43.
Ikeda, A. A., \& Feitosa, W. R. (2011). Segmentação de Mercado com Base em Coortes : uma investigação qualitativa Wilian Ramalho Feitosa. Revista Brasileira de Gestão de Negócios, 13(41), 359-375.

Instituto Nacional de Estudos e Pesquisas Educacionais Anísio Teixeira, Ministério da Educação. (2016). Índice Geral de Cursos (IGC). Resultados do IGC 2016. Recuperado de http:// portal.inep.gov.br/indice-geral-de-cursos-igc-

Kahle, L. R. (1983). Social Values and social change: adaptation to life in America. Nova Iorque: Praeger.

Lee, C.W., \& Liao, C.-S. (2009). The effects of consumer preferences and perceptions of Chinese tea beverages on brand positioninging strategies. British Food Journal, 111(1), 80-96.

Liu, G., Chapleo, C., Ko, W. W., \& Ngugi, I. K. (2015). The Role of Internal Branding in Nonprofit Brand Management: An Empirical Investigation. Nonprofit and Voluntary Sector Quarterly, 44(2), 319-339.

Moore, M., \& Carpenter, J. M. (2008). Intergenerational perceptions of market cues among US apparel consumers. Journal of Fashion Marketing and Management, 12(3), 323-337.

Motta, P. C., \& Schewe, C. (2008). Are marketing management decisions shaped during one's coming of age? Management Decision, 46(7), 1096-1110.

Noble, S. M., Haytko, D. L., \& Phillips, J. (2009). What drives college-age Generation Y consumers? Journal of Business Research, 62(6), 617-628.

Noble, S. M., \& Schewe, C. D. (2003). Cohort segmentation: An exploration of its validity. Journal of Business Research, 56(12), 979-987.

Pentecost, R., \& Andrews, L. (2010). Fashion retailing and the bottom line: The effects of 
generational cohorts, gender, fashion fanship, attitudes and impulse buying on fashion expenditure. Journal of Retailing and Consumer Services, 17(1), 43-52.

Pinar, M., Trapp, P., Girard, T., \& Boyt, T. E. (2011). Utilizing the brand ecosystem framework in designing branding strategies for higher education. International Journal of Educational Management, 25(7), 724-739.

Rauschnabel, P. A., Krey, N., Babin, B. J., \& Ivens, B. S. (2016). Brand management in higher education: The University Brand Personality Scale. Journal of Business Research, 69(8), 3077-3086.

Rokeach, M. (1973). The nature of human values. Free press.

Schewe, C., \& Meredith, G. (2004). Segmenting global markets by generational cohorts : Determining motivations by age. Journal of Consumer Behaviour, 4(1), 51-63.

Schwartz, S. H. (1994). Are there universal aspects in the structure and contents of human values? Journal of Social Issues, 50(4), 19-45.

Tang, N., Wang, Y., \& Zhang, K. (2017). Values of Chinese generation cohorts: Do they matter in the workplace? Organizational Behavior and Human Decision Processes, 143, 8-22.

Universidade Estadual do Rio Grande do Sul. (2010). Resolução Consun ñ 03/2010. Dispõe sobre o Regimento Geral da Universidade. Retrieved from http://www.uergs.edu.br/upload/ arquivos/201607/13105536-regimento-geraluniversidade.pdf

Wang, H. J. (2016). Green brand positioninging in the online environment. International Journal of Communication, 10, 1405-1427.

Weiss, D., \& Lang, F. R. (2009). Thinking about my generation: adaptive effects of a dual age identity in later adulthood. Psychology and Aging, 24(3), 729-734.

White, J. (2013). Thinking generations. British Journal of Sociology, 64(2), 216-247.

Young, A. M., \& Hinesly, M. D. (2012). Identifying Millennials' key influencers from early childhood: insights into current consumer preferences. Journal of Consumer Marketing, 29(2), 146-155. 


\section{Authors:}

1. Cristina M. Ostermann, Master in Management, UNISC, Santa Cruz do Sul, Brazil. E-mail: cris. ostermann@gmail.com

\section{ORCID}

(iD 0000-0001-8399-3519

2. Carlos Mello Moyano, Doctor in Management, UFRGS, Porto Alegre, Brazil. E-mail: carlos@unisc.br ORCID

(iD) 0000-0002-9923-3829

3. Jaime Laufer, Master in Production Engineering, UFSM, Santa Maria, Brazil. E-mail: jaime@unisc.br ORCID

(iD) 0000-0002-9824-1413

\section{Contribution of each author}

\begin{tabular}{lccc}
\hline Contribuiçáo & $\begin{array}{c}\text { Cristina Maria } \\
\text { Ostermann }\end{array}$ & $\begin{array}{c}\text { Carlos } \\
\text { Mello Moyano }\end{array}$ & Jaime Laufer \\
\hline 1. Definition of research problem & $\sqrt{ }$ & $\sqrt{ }$ & \\
2. Development of hypotheses or research questions & $\sqrt{ }$ & $\sqrt{ }$ \\
(empirical studies) & $\sqrt{ }$ & $\sqrt{ }$ \\
3. Development of theoretical propositions (theoretical work ) & $\sqrt{ }$ & \\
4. Theoretical foundation/ Literature review & $\sqrt{ }$ & & \\
5. Definition of methodological procedures & $\sqrt{ }$ & $\sqrt{ }$ \\
6. Data collection & $\sqrt{ }$ & \\
7. Statistical analysis & $\sqrt{ }$ & \\
8. Analysis and interpretation of data & $\sqrt{ }$ & \\
9. Critical revision of the manuscript & $\sqrt{ }$ & \\
10. Manuscript writing & & & \\
\hline
\end{tabular}

